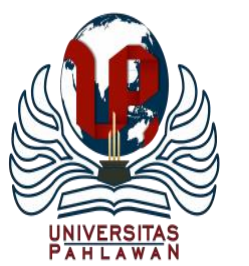

Jurnal Abdidas Volume 2 Nomor 1 Tahun 2021 Halaman 142-147

JURNAL ABDIDAS

http://abdidas.org/index.php/abdidas

\title{
Upaya Mengatasi Kesalahan Persepsi Masyarakat terhadap Tulisan Arab dan Arab Melayu di Desa Lubuk Garam Bengkalis
}

\author{
Salahuddin Al Asadullah \\ Program Studi Pendidikan Bahasa Arab, Jurusan Tarbiyah dan Keguruan, STAIN Bengkalis, Indonesia \\ E-mail: salahuddin.asadullah@yahoo.co.id
}

\begin{abstract}
Abstrak
Kegiatan pengabdian masyarakat ini bertujuan untuk melihat persepsi masyarakat tentang perbedaan antara tulisan Arab dan juga Arab Melayu. Hal ini didasari atas banyaknya salah persepsi masyarakat tentang tulisan tesebut. Kegiatan ini dibuat untuk mengubah persepsi tersebut. Pengabdian masyarakat ini dilakukan dengan metode pembagian data melalui grup media sosial. Dengan tahap perencanaan, pelaksanaan, dan evaluasi. Adapun hasil yang didapat adalah persepsi masyarakat tentang Arab dan Arab melayu sudah memiliki kemajuan baik itu dalam tahap pelaksanaan penelitian maupun dalam tahap evaluasi. Dalam tahap evaluasi, didapatkan hasil bahwa masyarakat sudah bisa membedakan antara tulisan Arab dan Arab Melayu. Hal ini sangat penting untuk dalam kehidupan agar tidak lagi adanya salah persepsi dalam membedakan Arab dan Arab Melayu terutama dalam peribadatan.
\end{abstract}

Kata kunci: persepsi masyarakat, Bahasa Arab, Arab Melayu

\section{Abstract}

This community service activity aims to see the community's perception of the difference between Arabic writing and Malay Arabic. This is based on the many misperceptions of society about the writing error. This activity is designed to change that perception. This community service is carried out by sharing data through social media groups. With the planning, implementation and evaluation stages. As for the results obtained, the public's perception of Arabic and Malay Arabic has progressed both in the research implementation stage and in the evaluation stage. In the evaluation stage, it was found that the community was able to distinguish between Arabic and Malay Arabic writing. This is very important for life so that there are no more misperceptions in differentiating Arab and Malay Arabic, especially in worship.

Keyword: public perception, Arabic, Arabic Malay

Copyright (c) 2021 Salahuddin Al Asadullah

$\triangle$ Corresponding author

Address : STAIN Bengkalis

Email : salahuddin.asadullah@yahoo.co.id

DOI $\quad:$ https://doi.org/10.31004/abdidas.v2i1.220 
143 Upaya Mengatasi Kesalahan Persepsi Masyarakat terhadap Tulisan Arab dan Arab Melayu di Desa Lubuk Garam Bengkalis-Salahuddin Al Asadullah

DOI: https://doi.org/10.31004/abdidas.v2i1.220

\section{PENDAHULUAN}

Bahasa Arab merupakan sebuah bahasa yang banyak digunakan oleh masyarakat dunia. Bahasa Arab merupakan bahasa resmi PBB. Bahasa Arab juga merupakan bahasa yang tertua di dunia.

Di antara bahasa-bahasa dunia tersebut, bahasa Arab menjadi bahasa tertua dan paling lama digunakan di dunia ini. Sejak Al-Qur'an diturunkan dan agama Islam semakin berkembang, penutur bahasa Arab semakin bertambah, hingga kini dituturkan oleh lebih dari 200.000 umat manusia. Bahasa ini digunakan secara resmi oleh kurang lebih 20 negara. Alasan lainnya, karena bahasa Arab adalah bahasa kitab suci dan tuntunan agama umat Islam sedunia, maka tentu saja, ia merupakan bahasa yang paling besar signifikannya bagi milyaran muslim sedunia, baik yang berkebangsaan Arab maupun bukan Arab. Bahasa Arab selain sebagai bahasa lisan, ia juga bahasa tulisan. Bahasa tulisan inilah yang telah membangun tradisi ilmiah di kalangan umat Islam. Secara historis dapat dibuktikan melalui karyakarya fenomenal ulama-ulama di berbagai bidang; di bidang tafsir, hadits, fiqih, aqidah dan di bidang ilmu-ilmu keislaman yang lainnya, tertulis dalam bahasa Arab. Karena sumber-sumber asli ajaran Islam dan ilmu-ilmu keislaman tertulis dalam bahasa Arab, maka sangatlah penting bagi umat Islam (Fakaubun, 2019).

Dalam sejarah peradaban Islam, tulisan yang dikenal ulama adalah tulisan yang digunakan dalam kitab suci Al-Qur'an, yaitu tulisan Arab dalam bahasa Arab. Ketika menyebarkan Islam ke tanah Melayu, maka ulama meminjam atau mempergunakan huruf-huruf Arab tersebut untuk menuliskan ajaran Islam dalam bahasa Melayu. Itulah yang disebut dengan Arab-Melayu yang berkembang hampir di seluruh daerah di Sumatera, dan juga dikenal di Malaysia, Brunei Darussalam dan Singapura (Kemenag RI, 2003).

Huruf Arab Melayu merupakan salah satu bentuk penulisan yang sering digunakan untuk menyampaikan sesuatu berita kepada orang lain, yang ditulis dalam bentuk huruf Arab tanpa menggunakan ejaan. Penulisan huruf Arab Melayu ini sedikit berbeda dengan penulisan huruf Arab yang terdapat dalam kitab suci umat beragama islam, yaitu Al-Qur'an. Huruf Arab Melayu bukan merupakan bentuk bahasa yang resmi digunakan oleh rakyat Indonesia, dikarenakan penggunaan huruf Arab Melayu ini semakin berkurang dan untuk membacanya dibutuhkan seseorang yang juga mampu membaca huruf Arab Melayu ini, juga dikarenakan penulisan bentuk huruf Arab Melayu ini tidak dimasukkan ke dalam kurikulum pendidikan di Indonesia. Namun banyak digunakan untuk penulisan kitab-kitab (Kemenag RI, 2003).

Pengetahuan yang harus dimiliki dalam menulis dan membaca tulisan huruf Jawi ialah mengetahui semua kaedah atau tata cara menulis dan membaca tulisan huruf Jawi, di antaranya yang terpenting adalah: mengenal dan mampu menuliskan aksara Jawi dalam semua bentuk perubahannya, yaitu huruf yang berdiri sendiri, berada di awal kata, di tengah kata dan di akhir. Di dalam masyarakat luas terutamanya di Bengkalis, bahasa Arab dan Arab Melayu merupakan dua aksara yang sering digunakan. Bahasa Arab 
144 Upaya Mengatasi Kesalahan Persepsi Masyarakat terhadap Tulisan Arab dan Arab Melayu di Desa Lubuk Garam Bengkalis-Salahuddin Al Asadullah

DOI: https://doi.org/10.31004/abdidas.v2i1.220

digunakan dalam kehidupan masyarakat terutama dalam peribadatan Islam yang identik dengan bahasa Arab, begitu juga dengan Arab Melayu yang sering digunakan dalam pembelajaran dan juga banyak digunakan dalam naskah-naskah klasik. Pengunaan huruf Jawi dalam penulisan berbentuk surat, telah digunakan lebih dari 400 tahun, menjadi sarana komunikasi antara raja-raja di kepulauan Nusantara dengan raja, pembesar dan pedagang-pedagang dari mancanegara (Pujiati, 2012).

Pada masyarakat Bengkalis, tulisan Arab dan Arab Melayu masih banyak yang salah dalam membedakan antara kedua tulisan ini. Padahal sejatinya, dua tulisan ini merupakan tulisan sangat berbeda jauh. Hal ini wajar, dikarekan antara tulisan Arab dan Arab melayu kaidah tersendiri dan mempunyai keunikan tersendiri pula, seperti tulisan Latin dan tulisan lainnya. Arab atau huruf Hijaiyah, kemudian ditambah dengan aksara Arab yang telah dimodifikasikan. Hal ini karena ada fonem bahasa Indonesia yang tidak dijumpai dalam bahasa Arab. Jadi, antara kedua tulisan ini hampir sama. Adapun tujuan penelitian ini adalah agar masyarakat tidak salah lagi mengidentifikasi antara tulisan Arab Melayu dan juga tulisan Arab.

\section{METODE}

Adapun sasaran penelitian ini adalah masyarakat Desa Lubuk Garam, Kabupaten Bengkalis yang berada pada grup WhatsApp Pemuda Dusun Suka Makmur dan juga grup WhatsApp Lubuk Garam City melalui handphone Android. Secara keseluruhan, jumlah anggota grup adalah 68 orang. Grup ini merupakan grup yang para pesertanya merupakan warga Lubuk Garam. Sehingga sangat memungkinkan untuk diadakan penelitian di grup ini.

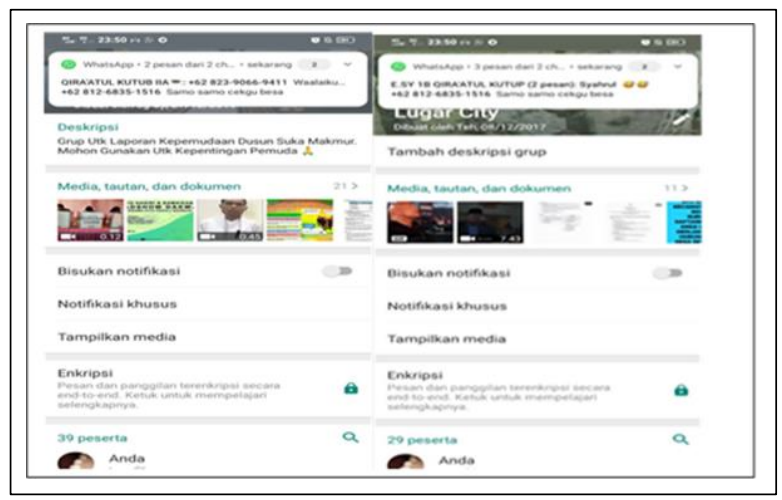

Gambar1. Jumlah Anggota Grup

Penelitian ini dilakukan pada tanggal 1 Januari 2021. Metode yang penulis lakukan dalam penelitian ini adalah dengan cara membagikan beberapa artikel dan juga data lainnya pada grupgrup masyarakat Desa Lubuk Garam, Kabupaten Bengkalis seperti grup Kepemudaan dan grup lainnya. Dengan tahapan sebagai berikut:

1. Perencanaan

Tahap perancanaan yang dilakukan adalah sebuah merencanakan materi-materi yang diberikan. Dalam tahap perencanaan ini, dilakukan juga penyusunan materimateri yang akan diberikan pada masyarakat.

2. Tahap Pelaksanaan

Dalam tahap pelaksanaan ini, dilakukan pembagian materi pada grup-grup media sosial masyarakat desa Lubuk Garam sebagai tempat penelitian penulis. 
145 Upaya Mengatasi Kesalahan Persepsi Masyarakat terhadap Tulisan Arab dan Arab Melayu di Desa Lubuk Garam Bengkalis-Salahuddin Al Asadullah

DOI: https://doi.org/10.31004/abdidas.v2i1.220

\section{Tahap Evaluasi}

Pada tahap evaluasi dilakukan, survei pengetahuan anggota grup sebagai sebuah survei terhadap pengetahuan masyarakat tentang membedakan Arab dan Arab Melayu. Dengan cara membagikan 2 tulisan ini.

\section{HASIL DAN PEMBAHASAN}

Dalam penulisan membagikan ke dalam 3 grup masyarakat. Dalam aktvitas ini, penulis mendapatkan respon positif dari masyarakat dan antusiasme yang tinggi dari anggota grup. Hal ini adanya tindak balas dari tahap evaluasi yang penulis lakukan pada penelitian ini.

1. Tahap Perencanaan

Dalam tahap perencanaan ini, penulis menyiapkan beberapa buah materi. Dimana materi ini merupakan materi yang berbentuk PDF berisikan materi yang mudah dipahami. Adapun materi yang penulis dapatkan adalah materi yang berasal dari Kemenag RI dengan judul Panduan Baca Tulis Arab Melayu. Lalu penulis memberikan materi tentang pengenalan huruf Arab dan Melayu sebagai perbandingan kedua aksara tersebut. Dan juga materi tentang membedakan antara Arab asli dan juga Arab Melayu.

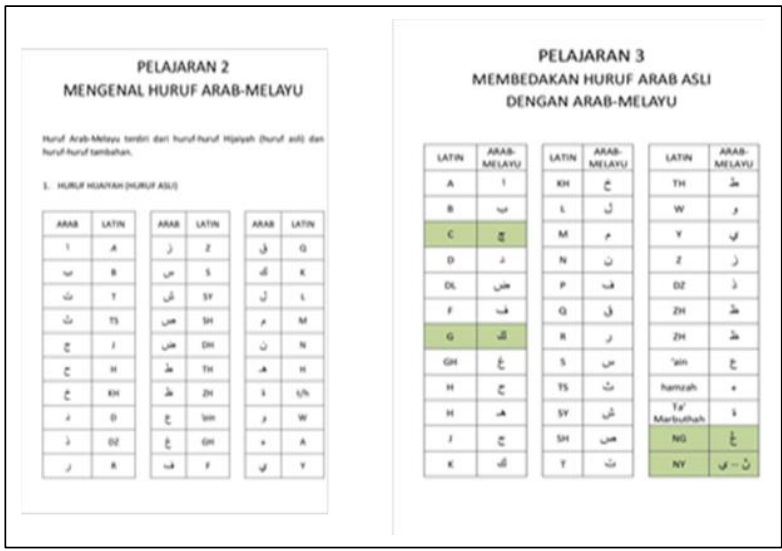

Gambar 2. Materi Pembelajaran Membedakan Tulisan Arab dan Arab Melayu

2. Proses Pelaksanaan

Setelah perencanaan materi, tahap selanjutnya yang penulis lakukan adalah tahap kegiatan pelaksanaan pembagian materi.

Dalam tahap ini, penulis membagikan materi berbentuk PDF tersebut ke dalam grup sebagai upaya memberikan pemahaman kepada masyarakat tentang perbedaan anatara Arab dan Arab Melayu.

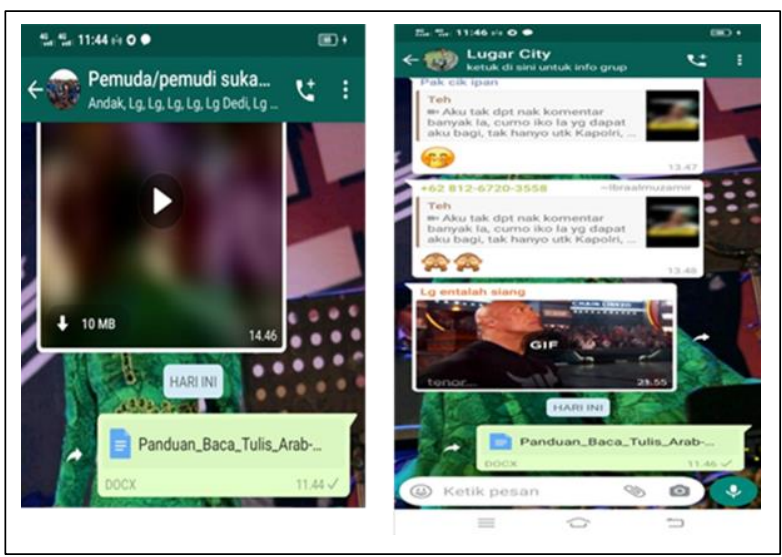

Gambar 3. Materi yang Dibagikan ke dalam Grup.

Berdasarkan informasi yang penulis dapatkan, banyak anggota grup yang membuka materi ini. Hal ini berarti adanya 
146 Upaya Mengatasi Kesalahan Persepsi Masyarakat terhadap Tulisan Arab dan Arab Melayu di Desa Lubuk Garam Bengkalis-Salahuddin Al Asadullah

DOI: https://doi.org/10.31004/abdidas.v2i1.220

antusiasme warga dalam mengikuti pembagian data ini.

3. Tahap Evaluasi

Pada tahap evaluasi, kepada masyarakat diberikan sebuah link, dimana link tersebut merupakan sebuah form yang berisikan tentang tulisan Arab dan Arab Melayu. Masyarakat diminta membedakan antara keduanya. Materi evaluasi berasal dari materi pada tahap pelaksanaan yang terdapat pada halaman 41 untuk tulisan Arab Melayu dan halaman 59 untuk tulisan Arab.
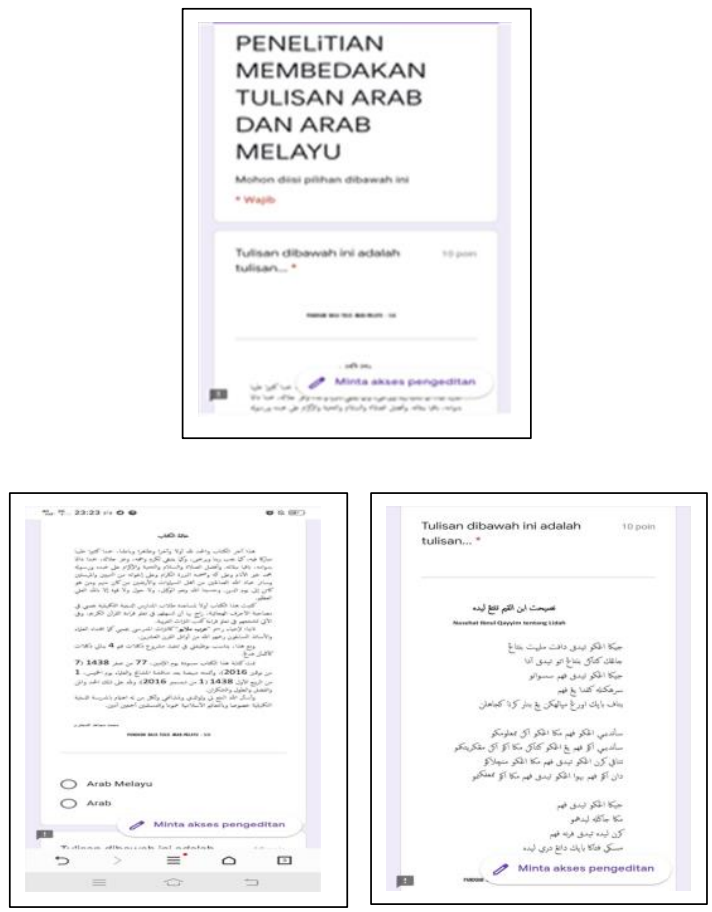

Gambar 4. Materi Evaluasi

Adapun hasil dari penyebaran link tersebut, didapati 50 responden telah merespon dengan hasil bahwa pengetahuan masyarakat tentang membedakan tulisan Arab dan Arab Melayu telah baik. Dengan 50 orang responden, sebanyak $36 / 72 \%$ dari
50 orang betul menjawab tulisan berbentuk tulisan Arab dan sebanyak 40/80\% dari 50 orang betul menjawab tulisan berbentuk tulisan Arab Melayu. Sebagaimana dibuktikan berdasarkan hasil berikut:
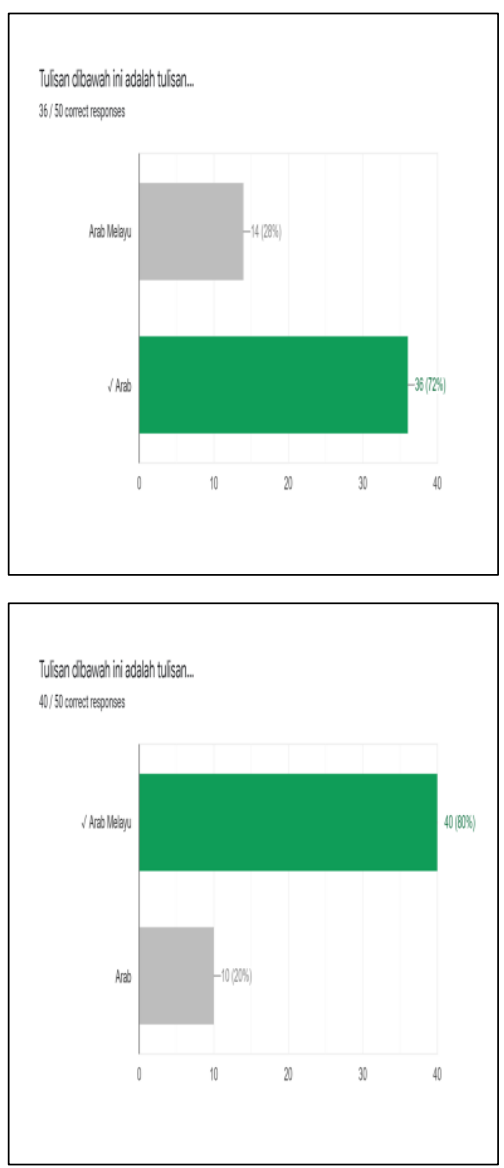

Gambar5. Hasil Survei Evaluasi

\section{SIMPULAN}

Kegiatan pembagian materi ini berjalan dengan baik. Dengan memberikan pembagian materi melalui sosial media ini, masyarakat mampu membedakan antara Tulisan Arab dan Arab Melayu. dan sebagai hasil positif dari kegiatan ini, telah terjadinya peningkatan pemahaman masyarakat terhadap tulisan Arab dan 
147 Upaya Mengatasi Kesalahan Persepsi Masyarakat terhadap Tulisan Arab dan Arab Melayu di Desa Lubuk Garam Bengkalis-Salahuddin Al Asadullah

DOI: https://doi.org/10.31004/abdidas.v2i1.220

Arab Melayu. Antusiasme warga juga sangat baik dalam melakukan kegiatan ini.

\section{UCAPAN TERIMAKASIH}

Penulis mengucapkan terimakasih kepada masyarakat desa Lubuk Garam yang telah memberikan kesempatan untuk melaksanakan salah satu Tri Dharma Perguruan Tinggi yakni penelitian dan juga pengabdian kepada masyarakat.

\section{DAFTAR PUSTAKA}

Aini, N. (2006). Perangkat lunak bantu mengenal huruf Arab melayu ke bentuk huruf latin bahasa Indonesia. Jurnal Ilmiah MATRIK, 8(3), 317-334.

Amanah, L. (n.d.). Urgensi Pembelajaran Bahasa Arab Dalam Pendidikan islam.

Anshori, T. (2019). Peran Bahasa Arab Dalam Pengembangan Ilmu Dan Peradaban Islam. https://doi.org/10.31219/osf.io/rnjcd

Fakaubun, A. F. F. (2019). Urgensi Bahasa Arab. November.

https://doi.org/10.31227/osf.io/ycvrh

Fitria, N., \& Fidesrinur, F. (2021). Pelatihan Peningkatan Strategi Pembelajaran Berbasis Kurikulum 2013. Jurnal Pemberdayaan Masyarakat Universitas Al Azhar Indonesia, 3(1),

41. https://doi.org/10.36722/jpm.v3i1.501

Kemenag RI. (2003). Paduan Baca Tulis Arab Melayu untuk MDTA. 1-60. https://admin.kemenag.go.id/files/jambi/file/f ile/pontren/Panduan_Baca_Tulis_ArabMelayu_untuk_MDTA.pdf

Madjid, M. D. (2018). Relasi Budaya ArabMelayu dalam Sejarah di Indonesia. Buletin Al-Turas, 19(2), 435-452. https://doi.org/10.15408/bat.v19i2.3729

Pujiati. (2012). Peranan Aksara Arab Melayu Untuk Membaca Khazanah Intelektual Naskah-Naskah Melayu Nusantara Pada
Pelajar Islam Di Kota Medan Sumatera Utara Indonesia. 4. http://pujiatiusu.blogspot.com/2012/06/peran an-aksara-Arab-melayu-untuk.html

Tamaji, S. T. (2020). Al-Fakkaar: Jurnal Ilmiah Pendidikan Bahasa Arab Vol. 1 No. 2 Agustus 2020 PEMBELAJARAN BAHASA. 1(2), 80-104.

Tentang, S., Memahami, U., Dalam, B., \& Bahasa, P. (n.d.). 121 Budaya Arab Dalam Pengajaran Bahasa Arab (.

Utari, S. A., \& Zebua, W. D. (2020). Peningkatan Kompetensi Civitas Universitas Muhammadiyah Jakarta Terkait Produksi Kampanye Public Relations di Masa Pandemi. Jurnal Pemberdayaan Masyarakat Universitas Al Azhar Indonesia, 3(1), 1. https://doi.org/10.36722/jpm.v3i1.479

Wahyuni, I. W., Ahmad, M., \& Mulyanti, S. (2011). Sikap Siswa Non Muslim dalam Mengikuti Pelajaran Arab Melayu. Jurnal AlHikmah, 8(1), 88-95.

Zainuri, M. (2019). Perkembangan Bahasa Arab Di Indonesia. Tarling : Journal of Language Education, 2(2), 231-248. https://doi.org/10.24090/tarling.v2i2.2926 